\title{
Douglas Walton, Fundamentals of Critical Argumentation
}

\author{
University Press, Cambridge, 2006, 343 pp
}

\section{Lewiński}

Published online: 9 September 2008

(C) The Author(s) 2008. This article is published with open access at Springerlink.com

Writing a good introductory textbook on argumentation and critical thinking is no easy task. What a model reader of such a book - that is, an undergraduate novice in the problematic of argumentation-needs, is probably a somewhat authoritative guidance to the field. "Authoritative" means that a textbook should be based on clearly laid out, easily comprehensible and theoretically consistent principles, or fundamentals. "Guidance" means that at the same time it should not present a ready-made closed doctrine, but instead leave enough room for students' own critical judgment and creativity. These two general requirements that a good textbook should meet are to a certain extent conflicting and hence the need for a skillful balancing of them: being too authoritative, or fundamental, would go exactly against the spirit of critical thinking; being too critical, open-minded and inconclusive would go against the goal of an introductory textbook.

This underlying difficulty in argumentation textbook-writing is suggested by the very title of Douglas Walton's Fundamentals of Critical Argumentation. The primary goal of this textbook is "to sharpen [a] critical attitude" of its readers by means of "a basic entry-level introduction to fundamentals" (p. xi). This introduction, as Walton projects, "is meant to be an advance over the many other textbooks on the market today that lack the kind of depth needed by a textbook that is based on an established scholarly discipline" (p. xi).

Quite undeniably, Fundamentals provide some basic methods of critical analysis of everyday argumentation in a way which adroitly avoids the two aforementioned pitfalls of either a principled dogmatism or an inconclusive criticism. Nevertheless, I would like to argue that if it leans towards one of these dangerous extremes, then it

\footnotetext{
M. Lewiński $(\square)$

Department of Speech Communication, Argumentation Theory and Rhetoric,

Faculty of Humanities, University of Amsterdam, Spuistraat 134,

1012 VB Amsterdam, The Netherlands

e-mail: M.Lewinski@uva.nl
} 
is the extreme of at times too scattered, hard-to-grasp critical guidelines which lack the much needed "depth [...] based on an established scholarly discipline".

Firstly, however, the book should be praised for its clear structure which consists of eight chapters, each of them divided into seven to nine distinct sections. Every section introduces a theoretical problem illustrated by many examples, and is followed by a set of relevant exercises. Finally, each chapter is rounded off with a summary of main points discussed. The sequence of problems covered also seems well-considered and suitable for this academic genre, as it leads readers in a step-bystep fashion from the very basics to somewhat more complicated problems of critical argumentation. The textbook starts with an introduction of basic "concepts useful for understanding arguments" (Chaps. 1 and 2) such as: arguments themselves, argumentative dialogues, different kinds of generalizations and arguments (deductive, inductive, presumptive), the notion of inconsistency and the distinction between arguments and explanations. Then, some major types of argumentation schemes, such as argument from expert opinion, from popular opinion, from sign, analogy or verbal classification are discussed (Chap. 3). This is followed by a presentation of four types of argumentation structures (convergent, linked, serial and divergent) (Chap. 4) and six types of dialogues (persuasion, inquiry, negotiation, information seeking, deliberation, and eristic) (Chap. 5). Further, the problems of linguistic bias and definitions in argumentation (Chap. 6) as well as of relevance (Chap. 7) are introduced. The last chapter deals with the subject of practical reasoning and related issues such as arguments from consequences and dilemmas (Chap. 8).

What is surprising, though, about the content of the textbook is a deliberate exclusion of the fundamental issue of argument evaluation. Instead, the book "concentrates primarily on argument identification and analysis" (p. xi). This choice seems rather surprising for a volume aimed at strengthening the "critical attitude" of its novice readers: after all, as Walton admits himself, "the ultimate goal of critical thinking is, of course, to evaluate arguments" (p. 139). And this is quite obvious throughout this textbook - the question of fallaciousness or soundness of everyday argumentation permeates almost every problem introduced in the textbook, notably the treatment of argumentation schemes, very often described in terms of traditional fallacies, such as ad hominem arguments, appeals to expert opinion, arguments from popular opinion, etc. Does it really make sense, then, to try to avoid an unavoidable fundamental problem of fallacies in Fundamentals of Critical Argumentation? Practically speaking, one may also argue that a 343-pages long introduction to critical argumentation with no explicit and systematic treatment of fallacies included is not the best "textbook on the market today" that a young, busy undergraduate student can get.

Unfortunately, the processes of identification and, especially, analysis of real-life argumentation-focal to the textbook-are treated somewhat superficially. It is especially here that the "depth [...] based on an established scholarly discipline", such as pragma-linguistics or discourse analysis, is missing. For instance, the discussion of argumentative indicators helpful in distinguishing between different argumentation structures (esp. convergent v. linked; pp. 148-152) is far from satisfying: mentioning just "my other reason" and "in addition" as indicators of 
convergent structures and "along with this" and "also required" as indicators of linked structures will not greatly help students in most less than crystal-clear cases of natural argumentation. Similarly, the chapter on the problems of loaded language and bias (Chap. 6) is one of the least convincing in the whole book. Moreover, as a textbook advertised as one that "teaches by using examples" and "uses realistic dialogues" it relies too heavily on constructed examples. Of course, the use of invented examples has its unquestionable advantages, such as control over the most relevant factors to be analysed, but there is a certain point where what is meant to be "realistic" is simply not quite "real". The practice of constructing examples, if used too extensively, may even lead to an impression among critical students that argumentation scholars, just like formal logicians, are trapped in a vicious circle of analysing what they themselves have created. A good example of that may be "The Dialogue on Tipping" (pp. 1-2) whose different analyses are presented throughout the book. To be sure, I do not want to suggest that it would be more pedagogical or illustrative to replace the constructed dialogue on tipping with, for instance, the notorious “I don't tip. I don't believe in it!" discussion from Quentin Tarantino's classic debut movie "Reservoir Dogs". Yet, a bit more attention to the problems of analysis of actual ordinary discourse would probably improve the quality and appeal of the book.

The identification of arguments-along the lines sketched in the textbook-may also be rather difficult to a novice student of argumentation. Consider the following case (p. 128):

All dolphins are classified as mammals.

Flipper is a dolphin.

Therefore, Flipper is a mammal.

While this looks like a familiar, classic example of a deductively valid syllogism where Socrates is replaced with Flipper and humans with dolphins, Walton introduces it under the heading of "inherently presumptive and defeasible" forms of reasoning (p. 84) as an "argument from verbal classification" (pp. 128-132). What exactly is the difference between these two ways of identifying the above argumentation? Is it just the predicate "classified as"? Or rather some important underlying philosophical distinction such as the one between realism and nominalism? Unfortunately, the textbook remains silent on this point and thus may leave its reader quite confused.

Similarly confounding may be the way "single" and "linked" arguments are presented in Chap 4. A single argument is one that "presents only one premise that is used all by itself as the basis offered to support the conclusion" (p. 169). The textbook gives one simple example of such a single structure:

Diseased cattle can transmit fatal diseases to humans who consume beef products. Therefore inspection of cattle for such diseases is essential for human safety (p. 139).

What one can probably see here, in accordance with the techniques of detecting "unstated premises" introduced in the very same chapter (pp. 157-162), is that this 
argument lacks one such unstated premise, which would probably look like this: "Anything that can be the cause of fatal human diseases should be carefully inspected as a means of an essential safety precaution". Therefore, the argument is not really single but a linked one, since it contains an unstated premise that only working with the second, stated premise supports the conclusion. And because such a filling, unstated premise can always be added, one may conclude that there is no such thing as a single argument according to Walton's definition of it. (A simple traditional solution that a single argument is the one that consists of two and only two premises jointly supporting one conclusion would clarify the matter. It is not, however, considered by the author.)

I want to believe that such difficulties (there are more of them) involve subtle distinctions which can possibly make Walton's exposition consistent. Still, a model novice reader of the textbook is not supposed, let alone obliged, to dig for such theoretical solutions outside of the textbook itself.

The book is also not free of some other minor shortcomings which may nevertheless impede a smooth grasp of the theoretical material by its readers. In general, it would benefit from a bit more careful editing-a very important factor in textbooks' evaluation. Some examples of editorial oversights lead to quite humorously paradoxical effects. Such is the case of an analysis of a set of statements (a)-(g) in terms of their (in-)consistency (pp. 45-46). The author explains that: "On the other hand, (a) is consistent with (f). [...] And clearly, (a) is inconsistent with (f) [...]". This indeed is an exercise in spotting inconsistency!

To finish with a short conclusion, I would say that this useful textbook probably requires somewhat more critical vigilance from its readers than the author would have wished.

Open Access This article is distributed under the terms of the Creative Commons Attribution Noncommercial License which permits any noncommercial use, distribution, and reproduction in any medium, provided the original author(s) and source are credited. 